Article

\title{
Increase in Absolute Leaf Water Content Tends to Keep Pace with That of Leaf Dry Mass-Evidence from Bamboo Plants
}

\author{
Weiwei Huang ${ }^{1}$, Gadi V. P. Reddy ${ }^{2}$, Yueyi Li ${ }^{1}$, Jorgen Bo Larsen ${ }^{3}$ and Peijian Shi ${ }^{1,4, *(\mathbb{D}}$ \\ 1 Bamboo Research Institute, College of Biology and Environment, Nanjing Forestry University, \\ Nanjing 210037, China; wh@njfu.edu.cn (W.H.); yueyilee@126.com (Y.L.) \\ 2 USDA-ARS-Southern Insect Management Research Unit, 141 Experiment Station Rd., P.O. Box 346, \\ Stoneville, MS 38776, USA; Gadi.Reddy@usda.gov \\ 3 Department of Geosciences and Natural Resource Management, The University of Copenhagen, \\ Rolighedsvej 23, DK-1958 Frederiksberg C, Denmark; jbl@ign.ku.dk \\ 4 Tropical Silviculture and Forest Ecology, University of Göttingen, Büsgenweg 1, 37077 Göttingen, Germany \\ * Correspondence: peijianshi@gmail.com; Tel.: +86-25-85427231 or +49-551-39-9556
}

Received: 20 July 2020; Accepted: 11 August 2020; Published: 12 August 2020

\begin{abstract}
Leaves, as the most important photosynthetic organ of plants, are intimately associated with plant function and adaptation to environmental changes. The scaling relationship of the leaf dry mass (or the fresh mass) vs. leaf surface area has been referred to as "diminishing returns", suggesting that the leaf area fails to increase in proportion to leaf dry mass (or fresh mass). However, previous studies used materials across different families, and there is lack of studies testing whether leaf fresh mass is proportional to the leaf dry mass for the species in the same family, and examining the influence of the scaling of leaf dry mass vs. fresh mass on two kinds of diminishing returns based on leaf dry mass and fresh mass. Bamboo plants (Poaceae: Bambusoideae) are good materials for doing such a study, which have astonishingly similar leaf shapes across species. Bamboo leaves have a typical parallel venation pattern. In general, a parallel venation pattern tends to produce a more stable symmetrical leaf shape than the pinnate and palmate venation patterns. The symmetrical parallel veins enable leaves to more regularly hold water, which is more likely to result in a proportional relationship between the leaf dry mass and absolute water content, which consequently determines whether the scaling exponent of the leaf dry mass vs. area is significantly different from (or the same as) that of the leaf fresh mass vs. area. In the present study, we used the data of 101 bamboo species, cultivars, forms and varieties (referred to as 101 (bamboo) taxa below for convenience) to analyze the scaling relationships between the leaf dry mass and area, and between leaf fresh mass and area. We found that the confidence intervals of the scaling exponents of the leaf fresh mass vs. dry mass of 68 out of the 101 taxa included unity, which indicates that for most bamboo species $(67.3 \%)$, the increase in leaf water mass keeps pace with that of leaf dry mass. There was a significant scaling relationship between either leaf dry mass or fresh mass, and the leaf surface area for each studied species. We found that there was no significant difference between the scaling exponent of the leaf dry mass vs. leaf area and that of the leaf fresh mass vs. leaf area when the leaf dry mass was proportional to the leaf fresh mass. The goodness of fit to the linearized scaling relationship of the leaf fresh mass vs. area was better than that of the leaf dry mass vs. area for each of the 101 bamboo taxa. In addition, there were significant differences in the normalized constants of the leaf dry mass vs. fresh mass among the taxa (i.e., the differences in leaf water content), which implies the difference in the adaptabilities to different environments across the taxa.
\end{abstract}

Keywords: Bambusoideae; diminishing returns; the proportional relationship; reduced major axis; the scaling relationship 


\section{Introduction}

The growth of plants cannot be separated from the contributions of leaves. The fundamental leaf functional traits (e.g., leaf biomass, water content, leaf shape, leaf surface area, etc.) profoundly affect a variety of biological processes, including plant growth, survival, reproduction and ecosystem function [1-3]. Leaf water content is intimately related to leaf turgor, growth, stomatal conductance, transpiration, photosynthesis and respiration [4]. Changes in leaf biomass can influence these leaf physiological processes. Our previous studies found that at the individual species level, one of the studied five Lauraceae, two of five Oleaceae and eight of seventeen bamboo species showed the leaf fresh weight increasing proportionally to leaf dry weight $[5,6]$.

The leaf area and leaf dry mass could represent the balance between the investment in growth and that in storage, and could be used to predict the growth strategy and response to environmental variations for leaves [7]. The scaling relationship between these two measures has been referred to as "diminishing returns," suggesting that increases in leaf surface area fail to keep pace with increases in leaf dry mass [8]. Our previous studies have found this same allometric relationship between the leaf dry mass and leaf surface area for five Lauraceae, five Oleaceae, eight Rosaceae, ten climbing species and seventeen bamboo species $[5,6,9,10]$. This "diminishing returns" phenomenon might occur because leaf dry matter is unevenly distributed in the leaf. This phenomenon could be explained by leaf phenotypic plasticity, in that there is an imbalance of dry mass investment between the two sides of a leaf. Plants normally invest more dry mass to the side facing the sunlight, and invest less mass in the shaded side [2,11].

Leaf water content is associated with leaf area increases. Wright et al. [12] analyzed the leaf data for 7670 species from 682 sites worldwide and showed that plants with large leaves tend to grow in wet, hot and sunny environments, whereas plants with small leaves usually grow in hot, sunny arid environments and at high latitudes and elevations. This is consistent with the findings that leaf size tended to decrease with decreasing water availability for 690 species at 47 sites spread widely throughout southeast Australia [13]. Under a soil-water deficit, large leaves face a greater risk of potentially serious heat damage at high air temperature than do small leaves. With decreasing site water availability, in order to avoid thermal stress when transpirational cooling is restricted, plants tend to produce smaller leaves [1]. An almost linear correlation between the leaf area and absolute leaf water content was found in several dicot plants [14]. Huang et al. [5,6] tested whether there were scaling relationships between the leaf fresh mass and leaf surface area using five Lauraceae, five Oleaceae and seventeen bamboo species, and they found that a significant scaling relationship of the leaf fresh mass vs. surface area existed for each of all the studied species. Furthermore, they found that the scaling relationship between the leaf fresh mass and area was stronger than that between the leaf dry mass and area for each studied species.

However, all the aforementioned previous studies investigated species across different families and yet used a limited number of species for each family. There is lack of studies using a large sample size of species from the same family to analyze the generality among species. Bamboo, as the world's fastest-growing, major non-wood forest product and wood substitute, has been widely acknowledged as an abundant, green and renewable resource and energy pool. The plants grow in tropical, subtropical, and warm temperate regions between $46^{\circ} \mathrm{N}$ and $47^{\circ} \mathrm{S}$. There are ca. 1300 Bambusoideae species worldwide, which belong to more than 150 genera; the total area of bamboo forests is about 31.5 million ha, which accounts for ca. $0.8 \%$ of the global forest area [15-17]. Bamboo plants are good materials for such a study, considering that the leaf shapes across species are very similar.

In the current study, we examined 10,045 leaves from 101 bamboo taxa from 17 genera, aiming to determine (i) whether the leaf fresh mass was proportional to the leaf dry mass, or if there was an allometric relationship, and what proportion of species showed a proportional or allometric relationship; (ii) what proportion of species showed "diminishing returns", referring to the scaling relationship between the leaf fresh/dry mass and leaf surface area; (iii) and whether the majority of the 
studied bamboo species exhibited a better scaling relationship between the leaf fresh mass vs. leaf surface area rather than the leaf dry mass vs. leaf surface area.

\section{Materials and Methods}

\subsection{Materials}

In total, 10,045 healthy, mature leaves were collected from 101 bamboo species, cultivars, forms and varieties from four sites (see Table S1 in the online Supplementary Data for details). Specifically, 48 species were collected from the Nanjing Forestry University campus, Nanjing, Jiangsu Province $\left(118^{\circ} 48^{\prime} 51^{\prime \prime} \mathrm{E}, 32^{\circ} 04^{\prime} 59^{\prime \prime} \mathrm{N}\right), 41$ species from the Baima Resource Nursery of Nanjing Forestry University, Nanjing, Jiangsu Province ( $119^{\circ} 07^{\prime} 42^{\prime \prime}$ E, $\left.31^{\circ} 37^{\prime} 55^{\prime \prime} \mathrm{N}\right)$, eight species from Tongzi County, Guizhou Province $\left(106^{\circ} 44^{\prime}-106^{\circ} 57^{\prime} \mathrm{E}, 28^{\circ} 13^{\prime}-28^{\circ} 43^{\prime} \mathrm{N}\right)$, and four species from the Southwest Forestry University campus, Kunming, Yunnan, Province $\left(102^{\circ} 45^{\prime} 26^{\prime \prime}\right.$ E, $\left.25^{\circ} 03^{\prime} 44^{\prime \prime} \mathrm{N}\right)$. The mean annual temperature at the two sites from Nanjing was $15^{\circ} \mathrm{C}$, and the annual precipitation was $1058 \mathrm{~mm}$ (southeast monsoon climate); for the site in Tongzi, the mean annual temperature was $14^{\circ} \mathrm{C}$, and the annual precipitation was $994 \mathrm{~mm}$ (subtropical monsoon climate); for the site in Kunming, the mean annual temperature was $15^{\circ} \mathrm{C}$, and the annual precipitation was $979 \mathrm{~mm}$ (south subtropical monsoon climate). The climate data were based on records from the China Climate Data online (www.data.cma.cn) for the period 1980-2018.

For each bamboo species, ca. 100 leaves were randomly collected from the middle canopy of different con-specific plants for each taxon. Mature leaves were collected from at least three different healthy adult individuals with similar age. Detailed information about the collection protocols and the list of 101 taxa can be found in Table S1 in the online Supplementary Materials and ref. [18].

\subsection{Measurements of Leaf Functional Traits}

Fresh leaves were weighed using an electronic balance (ME204/02, Mettler Toledo Company, Greifensee, Swizerland; measurement accuracy $0.0001 \mathrm{~g}$ ). They were then scanned, and the images were saved as bitmap images at 200 dpi resolution using a HP Scanjet 4850 scanner (Hewlett-Packard Company, Palo Alto, CA, USA). Adobe Photoshop (version: CC 2017) was used to obtain a leaf profile image in bitmap format. The protocols described by Shi et al. [19,20] and Su et al. [21] were used to measure the leaf area. After obtaining the leaf fresh weight and image, we dried the leaves to a constant dry weight in a ventilated oven at $80^{\circ} \mathrm{C}$ for at least $72 \mathrm{~h}$ and weighed them using the same electronic balance.

\subsection{Statistical Methods}

The following equation was used to describe the scaling relationships between the leaf traits at the species level (i.e., leaf dry mass vs. fresh mass, leaf dry mass vs. area, and the leaf fresh mass vs. area):

$$
y=a+b x
$$

where $y$ is the log-transformed response variable; $x$ is the log-transformed independent variable; $a$ is the intercept (i.e., the normalization constant); and $b$ is the slope (i.e., the scaling exponent). Reduced major axis regression was used to estimate the parameters [8]. The bootstrap percentile method was used to compare the significance of any difference in the estimated slope (and intercept) between the scaling relationship of the leaf dry mass vs. area and that of leaf fresh mass vs. leaf surface area for each of the 101 bamboo taxa [22,23]. All the statistical analyses were performed using the statistical software R (version 4.0.2) [24].

\section{Results}

The ratio of leaf dry mass to fresh mass was significantly different among the 101 bamboo taxa (Figure 1 and Table S2 in the online Supplementary Materials). The mean ratio ranged from 0.3413 
(Pleioblastus viridistriatus Makino) to 0.4905 (Phyllostachys bambusoides f. marliacea (Makino ex I. Tsuboi) Muroi). Within the same genus, different species also showed a large variation in the ratio of leaf dry mass to fresh mass (and Table S2 exhibited the significance of the difference in the ratio of any two taxa).

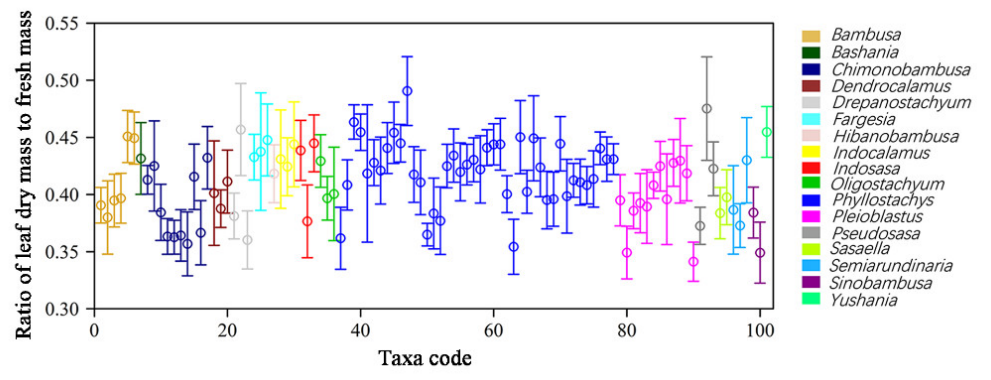

Figure 1. Comparison of the ratios of the leaf dry mass to the leaf fresh mass among 101 bamboo taxa. Different colors represent different genera of Bambusoideae. Each open circle and bar represent the mean and standard error of the leaf dry mass/leaf fresh mass ratios for each dataset.

There was a significant scaling relationship between the leaf fresh mass and dry mass for each individual bamboo species. Figure 2 shows the fitted linearized scaling relationships of the leaf dry mass vs. leaf fresh mass for four representative species (and the detailed fitted results for the remaining 97 bamboo taxa were tabulated in the Supplementary Materials, Table S3). The 95\% confidence intervals (CIs) of the scaling exponents of the leaf dry mass vs. fresh mass for 68 out of the 101 bamboo taxa included unity, which indicates that the leaf fresh mass is proportional to the leaf dry mass for most taxa $(=67.3 \%)$ (Table S3). The $95 \%$ CIs of the scaling exponents of the leaf dry mass vs. fresh mass of the remaining 33 taxa did not include unity (Table S3), which means that there were significant allometric relationships between the leaf fresh mass and dry mass for the 33 bamboo taxa. The scaling relationship of the leaf dry mass vs. fresh mass was statistically significant for each dataset, and there were 98 species with $r^{2}>0.90$ (Table S3). Phyllostachys aureosulcata McClure, Fargesia denudata T.P. Yi and Indosasa shibataeoides McClure had the lowest three $r^{2}$ values and yet $>0.82$.

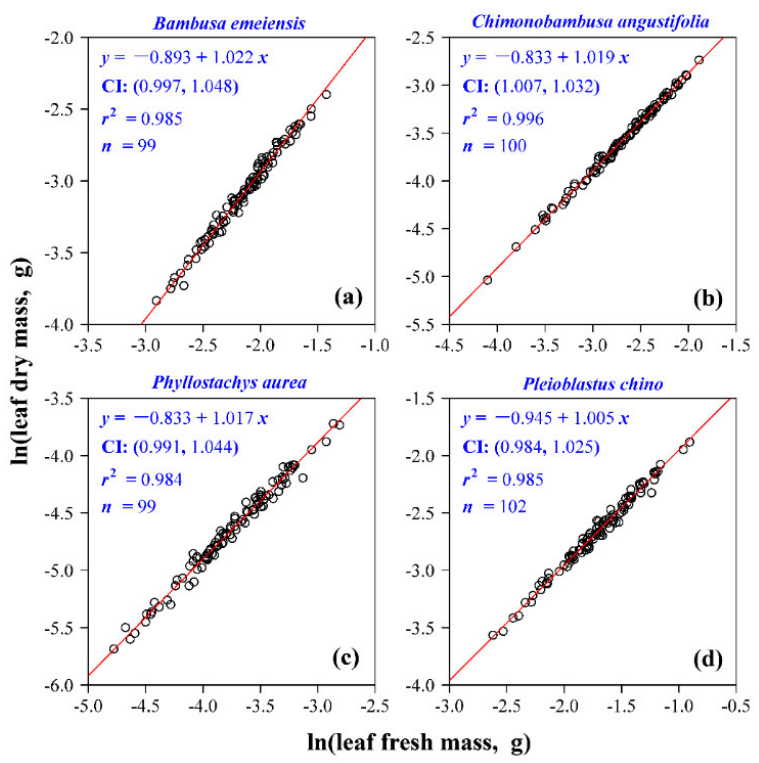

Figure 2. The fitted linearized scaling relationships of the leaf dry mass vs. fresh mass for four examples at the individual species level. Panels (a-d) represent different species. The open circles represent the observations, and the red straight line represents the reduced major axis regression line. In each panel, $y$ is the natural logarithm of the leaf dry mass in $g ; x$ is the natural logarithm of the leaf fresh mass in $g$; CI represents the $95 \%$ confidence interval of the slope; $r^{2}$ is the coefficient of determination that is used to measure the goodness of fit; and $n$ represents the number of leaves sampled. 
There was a significant scaling relationship between the leaf dry mass and surface area for each of the 101 bamboo taxa. Figure 3 shows the fitted linearized scaling relationships of the leaf dry mass vs. area for four representative species (and the detailed fitted results for the remaining 97 bamboo taxa were tabulated in Table S4 in the online Supplementary Materials). The lower bounds of the $95 \%$ CIs of the scaling exponents of the leaf dry mass vs. area for 83 bamboo taxa are greater than unity, which means that most species (82.2\%) showed significant allometric relationships (i.e., diminishing returns) between leaf dry mass and area (Table S4).

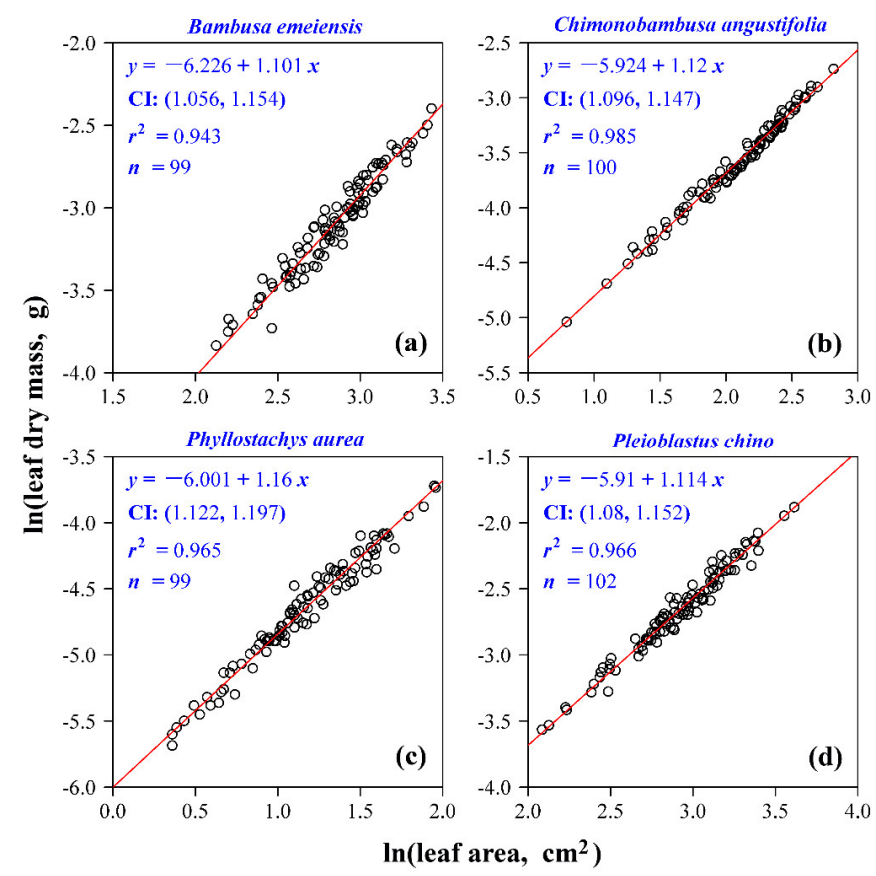

Figure 3. The fitted linearized scaling relationships of the leaf dry mass vs. area for four examples at individual species level. Panels (a-d) represent different species. The open circles represent the observations, and the red straight line represents the reduced major axis regression line. In each panel, $y$ is the natural logarithm of leaf dry mass in $\mathrm{g} ; x$ is the natural logarithm of leaf surface area in $\mathrm{cm}^{2}$; CI represents the $95 \%$ confidence interval of the slope; $r^{2}$ is the coefficient of determination that is used to measure the goodness of fit; and $n$ represents the number of leaves sampled.

There was also a significant scaling relationship between the leaf fresh mass and surface area for each of the 101 bamboo taxa. Figure 4 shows the fitted linearized scaling relationships of the leaf dry mass vs. area for four representative species (and the detailed fitted results for the remaining 97 bamboo taxa were tabulated in Table S5 in the online Supplementary Materials). The lower bounds of the 95\% CIs of the scaling exponents of the leaf fresh mass vs. area for 96 bamboo taxa are greater than unity, which means that most species $(95.0 \%)$ showed significant allometric relationships (i.e., diminishing returns) between the leaf dry mass and area (Table S5). This indicates that there is a larger number of bamboo taxa that follow the law of "diminishing returns" using leaf fresh mass rather than leaf dry mass.

The 95\% CIs of the intercepts' and slopes' differences between the linearized scaling relationship of the leaf dry weight vs. area and that of the leaf fresh weight vs. area of the 101 bamboo taxa are shown in Figure 5. Most of the 95\% CIs of the estimated intercepts ranged between -1.5 and -0.5 , and the $95 \%$ CIs all did not include zero (Figure 5a), which indicates that there is a significant difference in the normalized constants for each of the 101 bamboo tax. However, the $95 \%$ CIs of the estimated slopes' differences mostly ranged from -0.1 to 0.1 , and there were 68 out of the 101 bamboo taxa whose 95\% CIs included zero (Figure $5 \mathrm{~b}$ ). This means that there are no significant differences between the scaling exponent of the leaf dry mass vs. area and that of the leaf fresh mass vs. area for each of the 
68 datasets. If the leaf dry mass is proportional to the leaf fresh mass (Table S3), there is no significant difference between the scaling exponent of the leaf dry mass vs. area and that of the leaf fresh mass vs. area (Figure $5 b$ ).

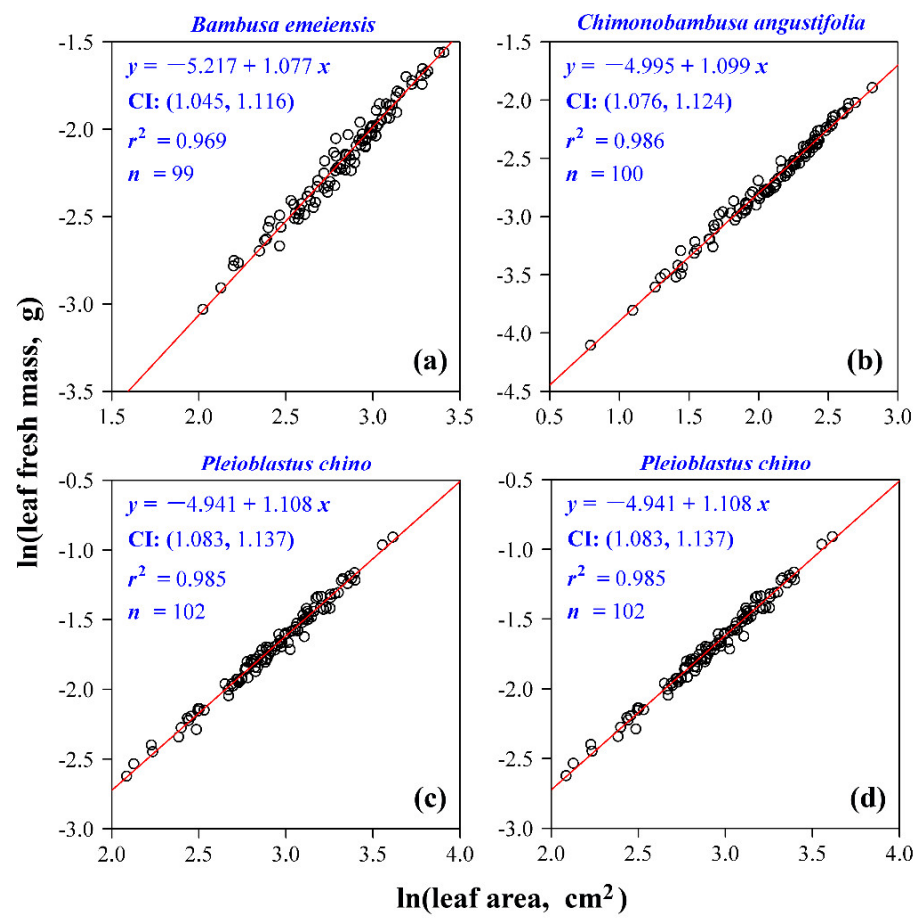

Figure 4. The fitted linearized scaling relationships of the leaf fresh mass vs. area for four examples at individual species level. Panels $(\mathbf{a}-\mathbf{d})$ represent different species. The open circles represent the observations, and the red straight line represents the reduced major axis regression line. In each panel, $y$ is the natural logarithm of the leaf fresh mass in $\mathrm{g} ; x$ is the natural logarithm of the leaf surface area in $\mathrm{cm}^{2}$; CI represents the $95 \%$ confidence interval of the slope; $r^{2}$ is the coefficient of determination that is used to measure the goodness of fit; and $n$ represents the number of leaves sampled.

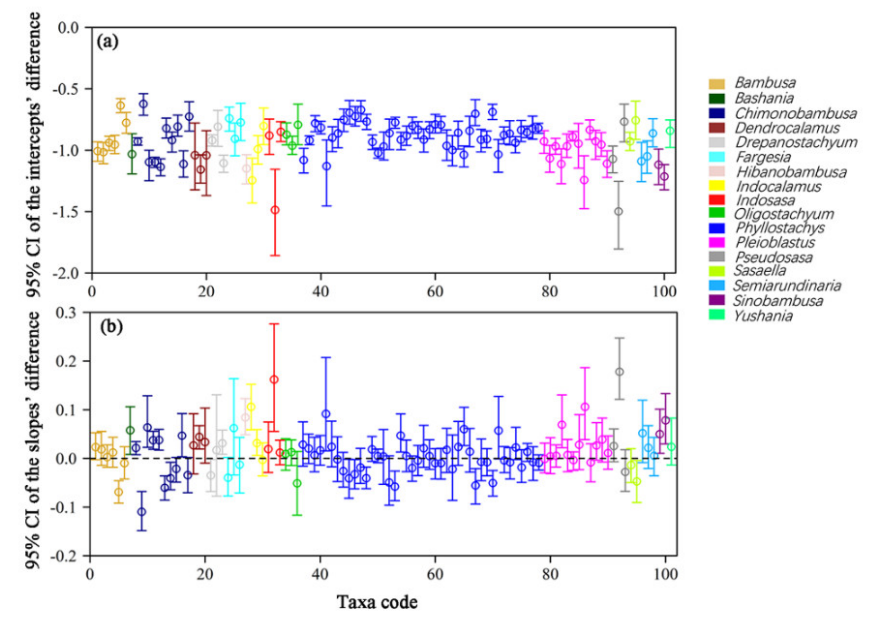

Figure 5. The $95 \%$ confidence interval (CI) of (a) the intercepts' difference and (b) the slopes' difference between the scaling relationship of the leaf dry weight vs. area and that of the leaf fresh weight vs. area. Different colors represent the investigated different genera of the 101 bamboo taxa. Each open circle and bar represent the mean and standard error of the $95 \%$ CI of the intercepts' difference (a) or the slopes' difference (b) for each dataset. To obtain the intercept and slope of each dataset, 3000 bootstrap replicates were used. 


\section{Discussion}

As noted, bamboo leaves are typically simple, and their overall shape is conserved throughout the whole subfamily. However, we found that the ratio of leaf dry mass to fresh mass was significantly different among the 101 bamboo taxa in this study. For most sampled bamboo taxa (68 of the studied 101 taxa) the $95 \%$ confidence intervals (CIs) of the scaling exponents of the leaf dry mass vs. fresh mass included unity (Table S3 in Supplementary Materials). This result shows that the leaf dry mass of the most studied taxa was proportional to the leaf fresh mass. In other words, the absolute leaf water content (= leaf fresh mass-leaf dry mass) kept pace with the leaf dry mass for these 68 bamboo species. Meanwhile, the $95 \%$ CIs of the scaling exponents of the leaf dry mass vs. fresh mass for the remaining 33 bamboo taxa did not include unity. Data from the two previous studies showed that for almost $50 \%$ of the studied bamboo species, the scaling exponents of the leaf dry mass vs. fresh mass approximately equaled to unity [5,6]; however, these two studies measured only seventeen bamboo species in total, and thus, did not provide a conclusive test of the general scaling relationship of the leaf dry mass vs. fresh mass of bamboo plants. The results of the present study contradict those of our previous studies, which found that only one of the five Lauraceae species studied and two of the five Oleaceae species studied had the $95 \%$ CIs of the scaling exponents of the leaf fresh mass vs. dry mass including unity [5]. This might be explained by the vascular architectures of the bamboo leaves with parallel venation, a structure both simpler and narrower than leaves with pinnate and palmate venation $[25,26]$. Leaves with more linear and evenly distributed veins might be more likely to result in a proportional relationship between the leaf dry mass and leaf fresh mass. In other words, water tends to be more regularly distributed in a leaf with the parallel venation pattern.

The above generality, across the 101 bamboo taxa, is consistent with previous studies that showed a significant exponential relationship between the leaf mass and leaf surface area in ferns, graminoids, forbs, shrubs, trees, vines and grasses $[5,6,8-10,27,28]$. The present study shows that for most bamboo species, i.e., 83 of the 101 bamboo taxa studied, the lower bounds of the $95 \%$ CIs of the scaling exponents of the leaf dry mass vs. area were larger than unity. For the scaling of leaf fresh mass vs. area, 96 of the 101 studied taxa had a lower bound of the $95 \%$ CI value for the scaling exponent that exceeded unity. This is consistent with previous findings that the law of "diminishing returns" exists in the relationship between the leaf biomass and leaf surface area [8]. For most sampled bamboo species, the increase in leaf dry or fresh mass per unit will result in a smaller leaf area increment. The allometric relationship between the leaf dry mass (or fresh mass) and area could be clarified by the leaf adaptation in the structure and physiology to the environment. Sack et al. [29] investigated a database of 485 globally distributed species and found that large leaves had a greater diameter for major veins and greater vein volume per area for mechanical support, and therefore intrinsically had larger vascular costs. Large simple leaves with high vein density are an angiosperm innovation [30], which could enable transpirational cooling to be combined with high photosynthetic rates [29]. We speculate that large leaves with higher vein density and greater major vein diameter might result in both higher water content and greater leaf dry mass per leaf unit area.

All the studied 101 bamboo taxa showed a stronger scaling relationship between the leaf fresh mass and area than that between the leaf dry mass and area. This is consistent with the findings of our previous studies on five Lauraceae, five Oleaceae, one Polygonaceae and seventeen bamboo species $[5,6,10]$. Absolute leaf water content is closely related with the leaf form and structure, which participates in the $C$ assimilation process for leaf mass accumulation and leaf expansion [31,32]. Leaf water status was intimately associated with the leaf turgor, growth, stomatal conductance, transpiration, photosynthesis and respiration [4]. Wright et al. [12] compiled the leaf size data for 7670 species from 682 non-agricultural sites worldwide, and found that plants with large leaves tend to grow in wet, hot and sunny environments, whereas plants with small leaves are mainly located at high latitudes or elevations or in hot, sunny and arid areas. In our study, the bamboo species with larger leaves grew in Yunnan and Guizhou, while the species grown in Nanjing have relatively smaller leaves. A large leaf may be selected for a plant in moist areas in order to have effective light 
capture and photosynthesis relative to biomass allocation [28]. The small-leaved species have more advantages for adaption to high latitudes and elevations than the large-leaved species. Larger leaves have thicker boundary layers, which usually slow down the sensible heat exchange with the soil, air and surrounding vegetation. Thus, these boundary layers render the leaves to be more susceptible to extreme temperatures, particularly those occurring on cold nights, and increase the potential for frost damage [12]. Leaves play an important role in the plant water transport system, which account for at least $30 \%$ of the whole-plant hydraulic resistance [33]. Efficient cuticular transpiration will provide sufficient nutrients with water from the soil to leaves [34]. Severe water stress could make stomata close and directly and indirectly affect the photosynthetic rate [35]. The balance of water use and plant growth is determined by water use efficiency and transpiration efficiency, which is very important in the $C$ assimilation for leaf expansion [36-38]. As the vital role of foliar water in leaf mass accumulation and leaf expansion, a stronger scaling relationship between the leaf fresh mass (= leaf dry mass + absolute leaf water content) and area was proved for 101 bamboo taxa.

\section{Conclusions}

The current study increased our understanding of the scaling relationships between the leaf fresh mass and leaf dry mass, and between the leaf mass and the leaf surface area of bamboo. For 68 of the 101 bamboo taxa studied, the $95 \%$ confidence intervals (CIs) of the scaling exponents of the leaf dry mass vs. fresh mass included unity, which indicates that the absolute leaf water content kept pace with the increase in leaf dry weight. There is a scaling relationship between the leaf dry mass (or fresh mass) and area for each studied species. Our results further confirmed the law of "diminishing returns", that the increase in leaf surface area could not keep pace with that of the leaf dry mass (or fresh mass). We found that there was no significant difference between the scaling exponent of the leaf dry mass vs. area and that of the leaf fresh mass vs. area when the leaf dry mass was proportional to the leaf fresh mass (i.e., the case that the $95 \% \mathrm{CI}$ of the scaling exponent of the leaf dry mass vs. fresh mass includes unity). Each of the 101 bamboo taxa had a stronger scaling relationship between the leaf fresh mass and surface area, than that between the leaf dry mass and area. This suggests that the absolute leaf water content should be considered when examining the scaling relationship between the bamboo leaf mass and leaf surface area. The influence of leaf vascular architectures (e.g., venation style, vein density, vein diameter) on the relationship between the leaf water mass and leaf dry mass, as well as that between leaf fresh mass and area, merits further investigation.

Supplementary Materials: The following are available online at http://www.mdpi.com/2073-8994/12/8/1345/s1, Table S1. Data collection information and scientific names of bamboos; Table S2. Comparison of the ratios of the leaf dry mass to fresh mass among the 101 bamboo taxa; Table S3. Fitted results for the scaling relationships between the leaf dry mass and leaf fresh mass of the 101 bamboo taxa; Table S4. Fitted results for the scaling relationships between the leaf dry mass and leaf surface area of the 101 bamboo taxa; Table S5. Fitted results for the scaling relationships between the leaf fresh mass and leaf surface area of 101 bamboo taxa.

Author Contributions: W.H. and P.S. designed this study and carried out the formal data analysis; W.H. wrote the initial draft, which was then further revised by G.V.P.R., Y.L., J.B.L. and P.S. All authors have read and agreed to the published version of the manuscript.

Funding: This research received no external funding.

Acknowledgments: We thank S.L. and Y.D. for publishing the raw data, which were used in the present study, in the Dryad repository (https://datadryad.org/stash/dataset/doi:10.5061/dryad.905qfttgb).

Conflicts of Interest: The authors declare no conflict of interest.

\section{References}

1. Tozer, W.C.; Rice, B.; Westoby, M. Evolutionary divergence of leaf width and its correlates. Am. J. Bot. 2015, 102, 367-378. [CrossRef] [PubMed]

2. Wang, P.; Ratkowsky, D.A.; Xiao, X.; Yu, X.; Su, J.; Zhang, L.; Shi, P. Taylor's power law for leaf bilateral symmetry. Forests 2018, 9, 500. [CrossRef] 
3. Shi, P.; Niinemets, Ü.; Hui, C.; Niklas, K.J.; Yu, X.; Hölscher, D. Leaf bilateral symmetry and the scaling of the perimeter vs. the surface area in 15 Vine species. Forests 2020, 11, 246. [CrossRef]

4. Kramer, P.J.; Boyer, J.S. Water Relations of Plants and Soils; Academic Press: San Diego, CA, USA, $1995 ;$ p. 495.

5. Huang, W.; Ratkowsky, D.A.; Hui, C.; Wang, P.; Su, J.; Shi, P. Leaf fresh weight versus dry weight: Which is better for describing the scaling relationship between leaf biomass and leaf area for broad-leaved plants? Forests 2019, 10, 256. [CrossRef]

6. Huang, W.; Su, X.; Ratkowsky, D.A.; Niklas, K.J.; Gielis, J.; Shi, P. The scaling relationships of leaf biomass vs. leaf surface area of 12 bamboo species. Glob. Ecol. Conserv. 2019, 20, e00793. [CrossRef]

7. Guo, Z.; Lin, H.; Chen, S.; Yang, Q. Altitudinal patterns of leaf traits and leaf allometry in Bamboo Pleioblastus amarus. Front. Plant Sci. 2018, 9, 1110. [CrossRef]

8. Niklas, K.J.; Cobb, E.D.; Niinemets, Ü.; Reich, P.B.; Sellin, A.; Shipley, B.; Wright, I.J. “Diminishing returns” in the scaling of functional leaf traits across and within species groups. Proc. Natl. Acad. Sci. USA 2007, 104, 8891-8896. [CrossRef]

9. Yu, X.; Hui, C.; Sandhu, H.S.; Lin, Z.; Shi, P. Scaling relationships between leaf shape and area of 12 Rosaceae species. Symmetry 2019, 11, 1255. [CrossRef]

10. Shi, P.; Li, Y.; Hui, C.; Ratkowsky, D.A.; Yu, X.; Niinemets, Ü. Does the law of diminishing returns in leaf scaling apply to vines? - Evidence from 12 species of climbing plants. Glob. Ecol. Conserv. 2020, 21, e00830. [CrossRef]

11. Smith, W.K.; Vogelmann, T.C.; DeLucia, E.H.; Bell, D.T.; Shepherd, K.A. Leaf form and photosynthesis: Do leaf structure and orientation interact to regulate internal light and carbon dioxide? BioScience 1997, 47, 785-793. [CrossRef]

12. Wright, I.J.; Dong, N.; Maire, V.; Prentice, I.C.; Westoby, M.; Díaz, S.; Gallagher, R.V.; Jacobs, B.F.; Kooyman, R.; Law, E.A.; et al. Global climatic drivers of leaf size. Science 2017, 357, 917-921. [CrossRef] [PubMed]

13. McDonald, P.G.; Fonseca, C.R.; Overton, J.M.; Westoby, M. Leaf-size divergence along rainfall and soil-nutrient gradients: Is the method of size reduction common among clades? Funct. Ecol. 2003, 17, 50-57. [CrossRef]

14. Hughes, A.P.; Cockshull, K.E.; Heath, O.V.S. Leaf area and absolute leaf water content. Ann. Bot. 1970, 34, 259-266. [CrossRef]

15. FAO. World Bamboo Resources. A Thematic Study Prepared in the Framework of the Global Forest Resources Assessment 2005. Non Wood Forest Products No. 18; Food and Agriculture Organization of the United Nations: Rome, Italy, 2007; p. 73. Available online: http://www.fao.org/3/a1243e/a1243e00.pdf (accessed on 1 July 2020).

16. FAO. Global Forest Resources Assessment 2010; Food and Agriculture Organization of the United Nations: Rome, Italy, 2010; p. 340. Available online: http://www.fao.org/forestry/fra/fra2010/en/ (accessed on 1 July 2020).

17. Liese, W.; Köhl, M. Bamboo: The Plant and Its Uses; Springer: Heidelberg, Germany, 2015.

18. Lin, S.; Niklas, K.J.; Wan, Y.; Hölscher, D.; Hui, C.; Ding, Y.; Shi, P. Leaf shape influences the scaling of leaf dry mass vs. area: A test case using bamboos. Ann. Forest Sci. 2020, 77, 11. [CrossRef]

19. Shi, P.; Ratkowsky, D.A.; Li, Y.; Zhang, L.; Lin, S.; Gielis, J. A general leaf area geometric formula exists for plants-Evidence from the simplified Gielis equation. Forests 2018, 9, 714. [CrossRef]

20. Shi, P.; Liu, M.; Ratkowsky, D.A.; Gielis, J.; Su, J.; Yu, X.; Wang, P.; Zhang, L.; Lin, Z.; Schrader, J. Leaf area-length allometry and its implications in leaf shape evolution. Trees Struct. Funct. 2019, 33, 1073-1085. [CrossRef]

21. Su, J.; Niklas, K.J.; Huang, W.; Yu, X.; Yang, Y.; Shi, P. Lamina shape does not correlate with lamina surface area: An analysis based on the simplified Gielis equation. Glob. Ecol. Conserv. 2019, 19, e00666. [CrossRef]

22. Efron, B.; Tibshirani, R.J. An Introduction to the Bootstrap; Chapman and Hall/CRC: New York, NY, USA, 1993.

23. Sandhu, H.S.; Shi, P.; Kuang, X.; Xue, F.; Ge, F. Applications of the bootstrap to insect physiology. Fla. Entomol. 2011, 94, 1036-1041. [CrossRef]

24. R Core Team. R: A Language and Environment for Statistical Computing; R Foundation for Statistical Computing: Vienna, Austria, 2020; Available online: https://www.R-project.org/ (accessed on 1 July 2020).

25. Shi, P.; Liu, M.; Yu, X.; Gielis, J.; Ratkowsky, D.A. Proportional relationship between leaf area and the product of leaf length and width of four types of special leaf shapes. Forests 2019, 10, 178. [CrossRef]

26. Shi, P.; Ratkowsky, D.A.; Gielis, J. The generalized Gielis geometric equation and its application. Symmetry 2020, 12, 645. [CrossRef]

27. Milla, R.; Reich, P.B. The scaling of leaf area and mass: The cost of light interception increases with leaf size. Proc. R. Soc. 2007, 274, 2109-2114. [CrossRef] [PubMed] 
28. Pan, S.; Liu, C.; Zhang, W.; Xu, S.; Wang, N.; Li, Y.; Gao, J.; Wang, Y.; Wang, G. The scaling relationships between leaf mass and leaf area of vascular plant species change with altitude. PLoS ONE 2013, 8, e76872. [CrossRef] [PubMed]

29. Sack, L.; Scoffoni, C.; McKown, A.D.; Frole, K.; Rawls, M.; Havran, J.C.; Tran, H.; Tran, T. Developmentally based scaling of leaf venation architecture explains global ecological patterns. Nat. Commun. 2012, 3, 837. [CrossRef] [PubMed]

30. Boyce, C.K. Research questions driving paleontology at the start of a new century, Paleontological society short course paleontological society papers. In From Evolution to Geobiology; Kelley, P.H., Bambach, R.K., Eds.; The Paleontological Society: Bethesda, MD, USA, 2008.

31. Chaves, M.M.; Pereira, J.S.; Maroco, J.; Rodrigues, M.L.; Ricardo, C.P.P.; Osório, M.L.; Carvalho, I.; Faria, T.; Pinheiro, C. How plants cope with water stress in the field, photosynthesis and growth. Ann. Bot. 2002, 89, 907-916. [CrossRef] [PubMed]

32. Ullah, S.; Skidmore, A.K.; Groen, T.A.; Schlerf, M. Evaluation of three proposed indices for the retrieval of

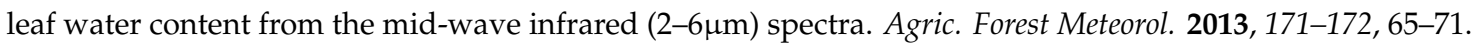
[CrossRef]

33. Sack, L.; Holbrook, N.M. Leaf hydraulics. Annu. Rev. Plant Biol. 2006, 57, 361-381. [CrossRef]

34. Yates, M.J.; Verboom, G.A.; Rebelo, A.G.; Cramer, M.D. Ecophysiological significance of leaf size variation in Proteaceae from the cape floristic region. Funct. Ecol. 2010, 24, 485-492. [CrossRef]

35. Cramer, M.D.; Hawkins, H.J.; Verboom, G.A. The importance of nutritional regulation of plant water flux. Oecologia 2009, 161, 15-24. [CrossRef]

36. Parkhurst, D.F.; Loucks, O.L. Optimal leaf size in relation to environment. J. Ecol. 1972, 60, 505-537. [CrossRef]

37. Vadez, V.; Kholova, J.; Medina, S.; Kakkera, A.; Anderberg, H. Transpiration efficiency: New insights into an old story. J. Exp. Bot. 2014, 65, 6141-6153. [CrossRef]

38. de Ollas, C.; Segarra-Medina, C.; González-Guzmán, M.; Puertolas, J.; Gómez-Cadenas, A. A customizable method to characterize Arabidopsis thaliana transpiration under drought conditions. Plant Methods 2019, 15, 89. [CrossRef] [PubMed] 